\title{
Advances in soft computing techniques for visual information-based systems
}

Published online: 2 March 2022

(C) Springer Science+Business Media, LLC, part of Springer Nature 2022

Multimedia Tools and Applications gratefully acknowledges the editorial work of the scholars listed below on the special issue entitled "Advances in Soft Computing Techniques for Visual Information-based Systems” (SI 1197).

Of 39 papers submitted, 10 were accepted for this issue after a stringent peer review process.

\section{Corresponding Guest Editor}

Shishir Kumar Shandilya

Vellore Institute of Technology, VIT Bhopal University, India

Email: shishirkumar.s@vitbhopal.ac.in

\section{Guest Editors}

\section{Neal Wagner}

Systems and Technology Research, Massachusetts, USA

Email: neal.wagner@stresearch.com

\section{Atulya K Nagar}

Liverpool Hope University, UK

Email: atulya.nagar@hope.ac.uk

Publisher's note Springer Nature remains neutral with regard to jurisdictional claims in published maps and institutional affiliations. 